\title{
Histone deacetylase inhibitors induce thymidine phosphorylase expression in cultured breast cancer cell lines
}

\author{
CINZIA PUPPIN $^{1}$, FABIO PUGLISI $^{2}$, MAURA PANDOLFI $^{3}$, CARLA DI LORETO $^{3}$ and GIUSEPPE DAMANTE ${ }^{1,4}$ \\ ${ }^{1}$ Dipartimento di Scienze e Tecnologie Biomediche, Università di Udine; ${ }^{2}$ Dipartimento di Oncologia, \\ Azienda Ospedaliero-Universitaria di Udine; ${ }^{3}$ Dipartimento di Scienze Mediche e Morfologiche, \\ Università di Udine; ${ }^{4}$ Istituto di Genetica, Azienda Ospedaliero-Universitaria di Udine, Udine, Italy
}

Received January 3, 2011; Accepted March 18, 2011

DOI: $10.3892 /$ or.2011.1310

\begin{abstract}
Thymidine phosphorylase (TP) is an enzyme involved in thymidine synthesis and degradation. The expression of this enzyme has been proposed as a predictive factor for the therapeutic benefit of capecitabine, which is a precursor of the drug 5'-fluorouracil. In fact, TP is the rate-limiting enzyme in the activation of capecitabine. Therefore, higher levels of TP are expected to sensitize cancer cells to capecitabine treatment. In the present study, using breast cancer cell lines, we found a correlation between TP mRNA and protein levels, suggesting that compounds able to increase TP gene expression also increase protein levels. Accordingly, we demonstrated that treatment of breast cancer MCF7 and MDA231 cell lines with histone deacetylase inhibitors, tricostatin A and suberoylanilide hydroxamic acid, increased TP both at the mRNA and protein level. The effects of histone deacetylase inhibitors were not found to occur via the cytokine $\mathrm{TNF} \alpha$, a known inducer of TP expression. Our findings suggest a strategy to sensitize breast cancer cells to capecitabine treatment.
\end{abstract}

\section{Introduction}

Thymidine phosphorylase (TP), also known as plateletderived endothelial cell growth factor, is an enzyme involved in thymidine synthesis and degradation (1). TP induces cell proliferation, endothelial cell chemotaxis in vitro and angiogenesis in vivo $(2,3)$. TP is detectable in healthy and tumor tissues, yet TP expression in solid tumors appears to be increased 3- to 10 -fold with respect to healthy adjacent tissues $(4,5)$. In the last few years, it has been shown that TP may have multiple roles in human cancer. Data suggest that TP may increase the metastatic potential of cancer cells by inducing the

Correspondence to: Professor Giuseppe Damante, Dipartimento di Scienze e Tecnologie Biomediche, Università di Udine, Piazzale Kolbe 1, 33100 Udine, Italy

E-mail: giuseppe.damante@uniud.it

Key words: breast cancer, thymidine phosphorylase, histone deacetylase inhibitor expression of several matrix metalloproteinases (6). In addition, TP acts in the salvage cascade of DNA metabolism in response to various types of stresses (7). TP exhibits a pro-angiogenic activity, and its overexpression was found to significantly correlate with an increase in neovascularization and poor prognosis (8). In breast cancer, the prognostic role of TP is not clear since conflicting results have been reported in different studies (9-11).

TP expression has also been evaluated as a predictive factor for the therapeutic benefit of capecitabine, which is a precursor of the active drug 5'-fluorouracil (5'-FU). TP is the final enzyme responsible for conversion to the active drug and represents the rate-limiting enzyme in the activation of capecitabine, suggesting that sensitivity of tumor cells to this prodrug is enhanced by increased TP expression (12). However, conflicting results have been obtained regarding the predictive value of TP expression in subjects treated with capecitabine (13-17).

The contrasting results obtained in the evaluation of TP expression as a prognostic or predictive factor are related to the method of detection. Most approaches for evaluating TP expression in tumor tissues include immunohistochemistry (IHC) and quantitative evaluation of mRNA by PCR (RT-PCR). Several reports have shown inconsistency between the two methods in evaluating TP expression (18). This lack of correlation between IHC and RT-PCR may be due either to a difference in what or how these methods measure. In the first case, the lack of consistency between IHC and RT-PCR is caused by a dissociation between mRNA and protein levels (and, therefore, by a post-mRNA control of protein levels). In the second case, the dissociation stems from epistemologic biases that are intrinsic to each method. In the present study, TP protein levels were found to correlate with TP mRNA in the breast cancer cell lines. Moreover, we investigated a strategy to increase TP protein levels in breast cancer cells.

\section{Materials and methods}

Cell lines and viability assay. SKBR3, MDA231 and MCF7 cells were cultured in DMEM medium with $10 \%$ fetal calf serum (Gibco), treated or not with HDAC inhibitors: tricostatin A (TSA) (Sigma) (300 nM for $24 \mathrm{~h}$ ) and suberoylanilide hydroxamic acid (SAHA) (Cayman) $(1.5,3$ and $6 \mu \mathrm{M}$ 
Table I. Oligonucleotide primers and probes used in the quantitative PCR reactions.

\begin{tabular}{llll}
\hline & \multicolumn{2}{c}{ Forward } & \multicolumn{2}{c}{ Reverse } & Probe \\
\hline TP & CCTGCGGACGGAATCCT & GCTGTGATGAGTGGCAGGCT & CAGCCAGAGATGTGACAGCCACCGT \\
TNF $\alpha$ & GGAGAAGGGTGACCGACTCA & TGCCCAGACTCGGCAAAG & CGCTGAGATCAATCGGCCCGACTAT \\
\hline
\end{tabular}

for 24,48 or $72 \mathrm{~h}$ ). In the viability assays, $3 \mathrm{~h}$ before the end of treatment with SAHA, a solution containing MTT $(4 \mathrm{mg} / \mathrm{ml}$ in PBS) was added to $10 \%$ of the culture medium. After $3 \mathrm{~h}$, the medium was removed, and the cells were lysed with DMSO. The absorbances of the samples were analyzed at a wavelength of $540 \mathrm{~nm}$ with background subtraction at $690 \mathrm{~nm}$. All experimental points were run in quadruplicate.

Quantitative RT-PCR. Total RNA from the cell lines was extracted with the RNeasy Protect Mini Kit (Qiagen) according to the manufacturer's instructions. Total RNA $(1 \mu \mathrm{g})$ was reverse transcribed to single-stranded cDNA using random exaprimers and $200 \mathrm{U}$ MMLV reverse transcriptase (Invitrogen) in a final volume of $20 \mu \mathrm{l}$ at $42^{\circ} \mathrm{C}$ for $50 \mathrm{~min}$ followed by heating at $70^{\circ} \mathrm{C}$ for $15 \mathrm{~min}$. Real-time PCRs were performed using the ABI Prism 7300 Sequence Detection System (Applied Biosystems). Oligonucleotide primers and probes for TP and TNF $\alpha$ are described in Table I. Oligonucleotide primers and probes for the endogenous control $\beta$-glucuronidase (GUS) were previously described (19). A $25-\mu 1$ reaction mixture containing $5 \mu \mathrm{l}$ cDNA template, $12.5 \mu 1$ TaqMan Universal PCR master mix (Applied Biosystems) and $1.25 \mu \mathrm{l}$ primer probe mixture was amplified using the following thermal cycler parameters: incubation at $50^{\circ} \mathrm{C}$ for $2 \mathrm{~min}$ and denaturation at $95^{\circ} \mathrm{C}$ for $10 \mathrm{~min}$, then 40 cycles of the amplification step (denaturation at $95^{\circ} \mathrm{C}$ for $15 \mathrm{sec}$ and annealing/extension at $60^{\circ} \mathrm{C}$ for $\left.1 \mathrm{~min}\right)$. The $\Delta \mathrm{CT}$ method, by means of SDS software (Applied Biosystems), was used to calculate the mRNA levels.

Western blot analysis. Total protein extracts were obtained from the cell pellet by resuspending them with total lysis buffer [10 mM Tris-HCl (pH 7.5), 1 mM EDTA, 0.5\% NP-40, $150 \mathrm{mM} \mathrm{NaCl}, 1 \mathrm{mM}$ DTT, 10\% glycerol; supplemented with PMSF and protease inhibitors]. The lysate was subsequently sonicated three times for $10 \mathrm{sec}$ and centrifuged at $13,000 \mathrm{x} \mathrm{g}$ for $10 \mathrm{~min}$ at $4^{\circ} \mathrm{C}$.

The supernatant was then collected and utilized for Western blot analysis. Total protein extracts $(25 \mu \mathrm{g})$ were electrophoresed on $12 \%$ SDS-PAGE. Proteins were then transferred to nitrocellulose membranes which were saturated by incubation for $1 \mathrm{~h}$ with $5 \%$ non-fat dry milk in PBS/0.1\% Tween-20. The membranes were then incubated overnight with a mouse monoclonal anti-thymidine phosphorylase antibody (clone P-GF.44C; Abcam). After three washes with PBS/0.1 Tween-20, the membranes were incubated with antimouse immunoglobulin coupled to peroxidase (Sigma). After $2 \mathrm{~h}$ of incubation, the membranes were washed three times with PBS/0.1\% Tween-20, and the blots were developed using Chemidoc XRS (BioRad) using a chemiluminescence procedure (Amersham Bioscience). Polyclonal anti-Ran antibody (Sigma) was used as the control.
Immunohistochemistry. The mammary cell lines were cultured on microscope slides, air-dried for $60 \mathrm{~min}$, fixed with ice-cold acetone for $10 \mathrm{~min}$ and washed with PBS/Tween-20 three times for $5 \mathrm{~min}$. After antigen retrieval in a water bath at $98^{\circ} \mathrm{C} \mathrm{(40} \mathrm{min} \mathrm{in} 1 \mathrm{mM}$ EDTA buffer, $\mathrm{pH}$ 8.0) and treatment with PBS/20\% (w/v) normal serum goat antibody for $20 \mathrm{~min}$, the samples were incubated with the mouse anti-thymidine phosphorylase antibody used for the Western blotting (1:100 overnight at $4^{\circ} \mathrm{C}$ ). For detection of staining, the EnVision ${ }^{+} /$ HPR Detection System (Dako, A/S) was used according to the manufacturer's recommendations. For each experiment, a negative control was included in which the primary antibody was replaced by mouse ascites.

\section{Results}

TP mRNA (assessed by quantitative RT-PCR) and protein levels (assessed by IHC) frequently do not correlate with each other when used as prognostic indicators and response predictors in breast cancer patients. This lack of correlation may be due to a dissociation between mRNA and protein levels. Thus, SKBR3, MDA231 and MCF7 breast cancer cell lines were used to investigate this lack of consistency. As shown in Fig. 1A, the TP mRNA levels in SKBR3 cells were significantly higher than those observed in the MDA231 and MCF7 cells. This difference was paralleled at the protein level. By using either Western blot or immunohistochemistry, the TP protein levels detected in the SKBR3 cells were much higher than those detected in the MDA231 and MCF7 cells (Fig. 1B-D). These data indicate that TP mRNA levels are the major determinant of TP protein levels. Thus, in order to increase tumor responsiveness to capecitabine treatment, a possible approach may consist in using compounds able to increase gene expression, and inhibitors of histone deacetylases (HDACi) (20) may be effective. Therefore, we compared the mRNA and protein levels of TP in SKBR3, MDA231 and MCF7 cells treated or not with TSA, an HDACi commonly used in vitro. The cell lines were treated with $300 \mathrm{nM}$ of TSA for $24 \mathrm{~h}$, and the TP mRNA and protein levels were evaluated by quantitative RT-PCR and Western blot analysis, respectively. Quantification of the results of these assays are shown in Fig. 2. In the SKBR3 cells, TSA induced a slight reduction in TP mRNA and protein levels, while in the MDA231 and MCF7 cells, TSA treatment induced a significant increase in TP either at the mRNA or protein level. These data suggest that TSA is able to increase TP mRNA and protein levels only in cells in which TP expression is low (such as in the MDA231 and MCF7 cell lines). Moreover, the correlation between mRNA and protein levels upon TSA treatment confirms that TP protein levels are mostly controlled by TP gene transcription. To substantiate the possibility of using HDACi to increase 

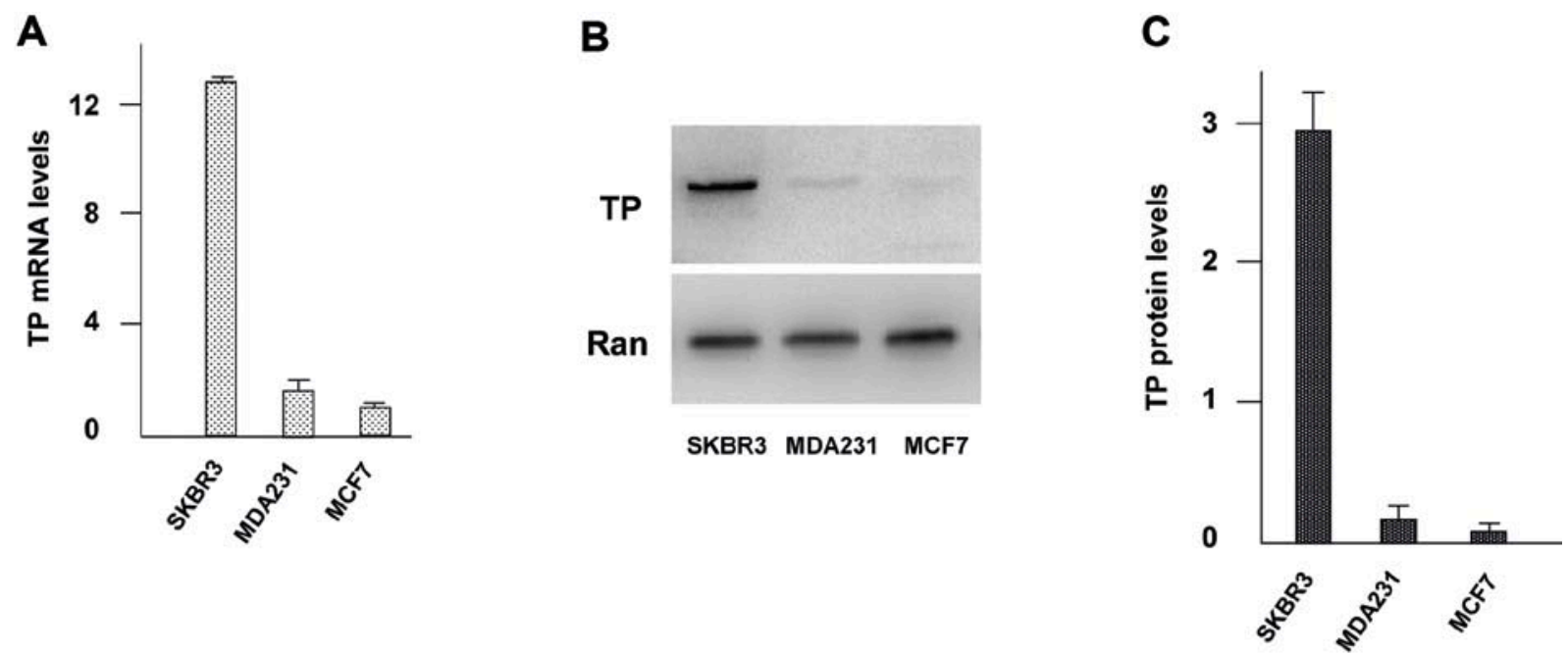

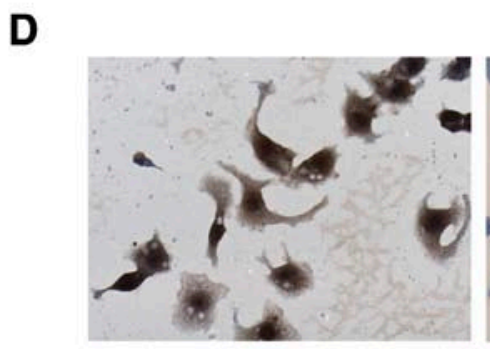

SKBR3

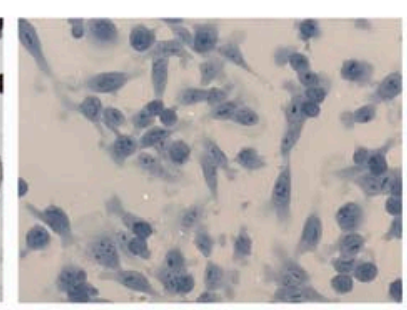

MDA231

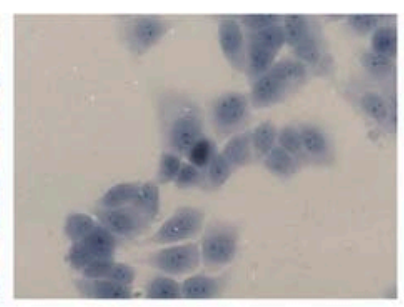

MCF7

Figure 1. Thymidine phosphorylase (TP) expression in breast cancer cell lines. SKBR3, MDA231 and MCF7 cells were analyzed for TP mRNA and protein levels. (A) TP mRNA levels. (B) Representative Western blot image of TP protein levels. (C) Quantification of the Western blot analysis. (C) Immunohistochemical detection of TP protein levels. Each bar in A and C indicates the mean value \pm SD of three independent determinations.

A

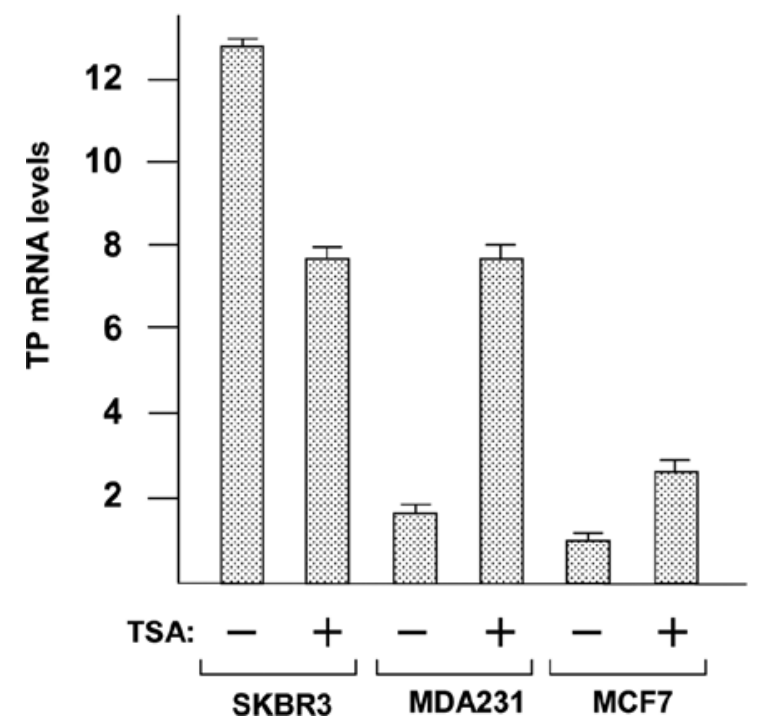

B

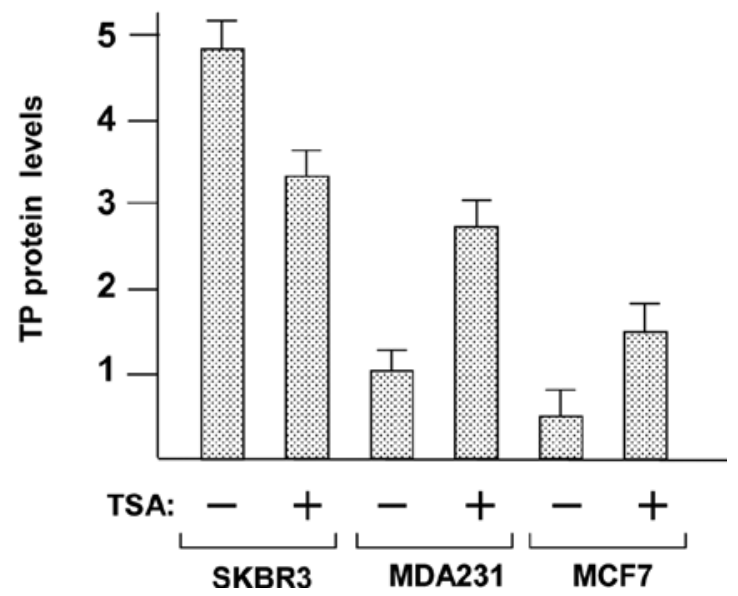

Figure 2. Effects of TSA on thymidine phosphorylase (TP) expression. SKBR3, MDA231 and MCF7 cells were treated with $300 \mathrm{nM}$ TSA for $24 \mathrm{~h}$ and TP mRNA and protein levels were measured as described in Materials and methods. (A) TP mRNA levels. (B) TP protein levels. In both panels, each bar indicates the mean value $\pm \mathrm{SD}$ of three independent determinations.

TP protein levels in vivo, thus further sensitizing tumor cells to capecitabine, SAHA, an HDACi investigated in several clinical trials, was used (21). In the first experiment, the sensi- tivity of MDA231 and MCF7 cell lines to SAHA in terms of cell viability was evaluated. MCF7 cells were more sensitive than MDA231 to SAHA treatment (Fig. 3). After treatment 

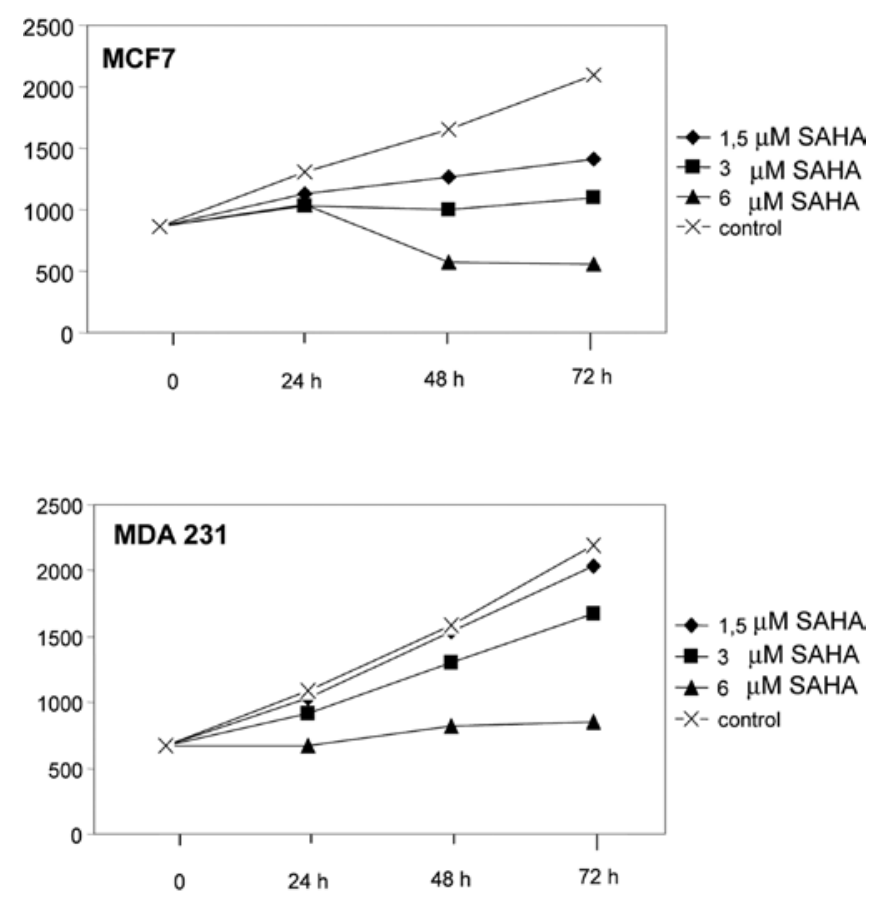

Figure 3. Effects of SAHA on the cell viability of the breast cancer cell lines. MCF7 and MDA231 cell lines were treated with the indicated concentrations of SAHA. After 24, 48 and $72 \mathrm{~h}$, cell viability was evaluated by MTT assay. Each point represents the mean value of four independent determinations. For each point SD was $<10 \%$.

with $1.5 \mu \mathrm{M}$ SAHA for 24 and $48 \mathrm{~h}$, reduced cell viability was detectable only in the MCF7 cells. Based on these results, the effects of SAHA treatment on TP mRNA and protein levels were evaluated using 3 and $6 \mu \mathrm{M}$ SAHA for $24 \mathrm{~h}$. As shown in Fig. 4A and B, the SAHA treatment induced a dose-dependent increase in TP mRNA and protein levels in the MDA231 and MCF7 cells. Quantification of the signals detected in the Western blot analysis indicated that, in both cell lines, treat-

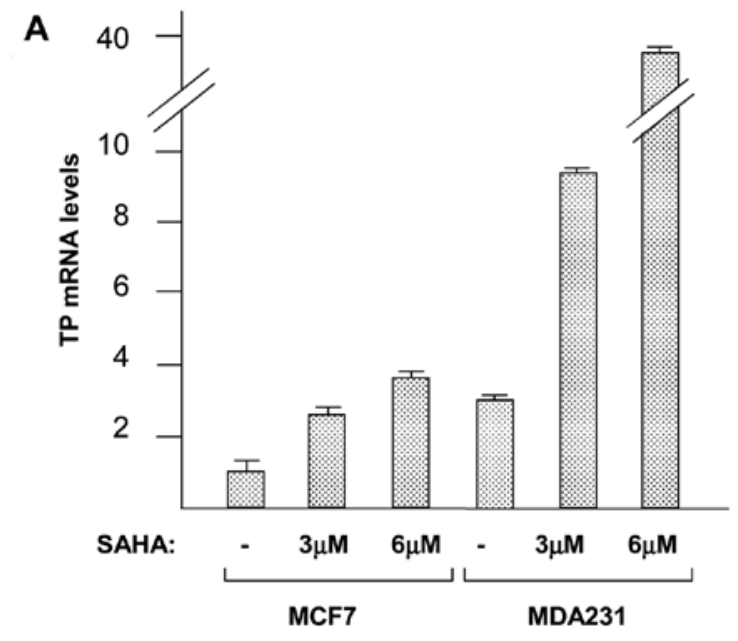

B

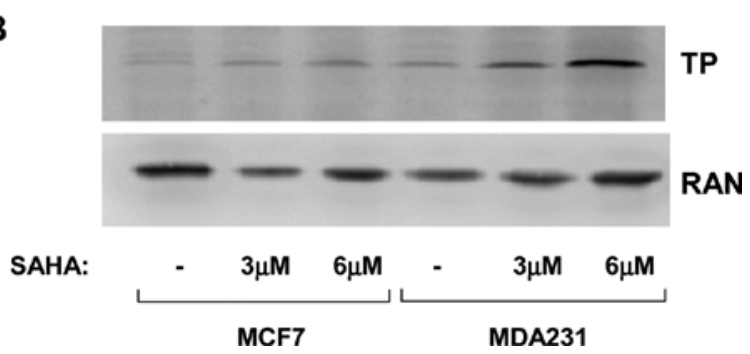

Figure 4. Effects of SAHA on TP mRNA and protein levels. MCF7 and MDA231 cells were treated with the indicated concentrations of SAHA for $24 \mathrm{~h}$. Then TP mRNA and protein levels were evaluated as described in Materials and methods. (A) TP mRNA levels (each bar indicates the mean value $\pm \mathrm{SD}$ of three independent determinations). (B) Western blot image.

ment with $6 \mu \mathrm{M}$ SAHA increased the TP protein levels 5- to 6-fold (data not shown).

TP gene expression was previously found to be controlled by TNF $\alpha$ (22). Thus, an increase in TP gene expression upon
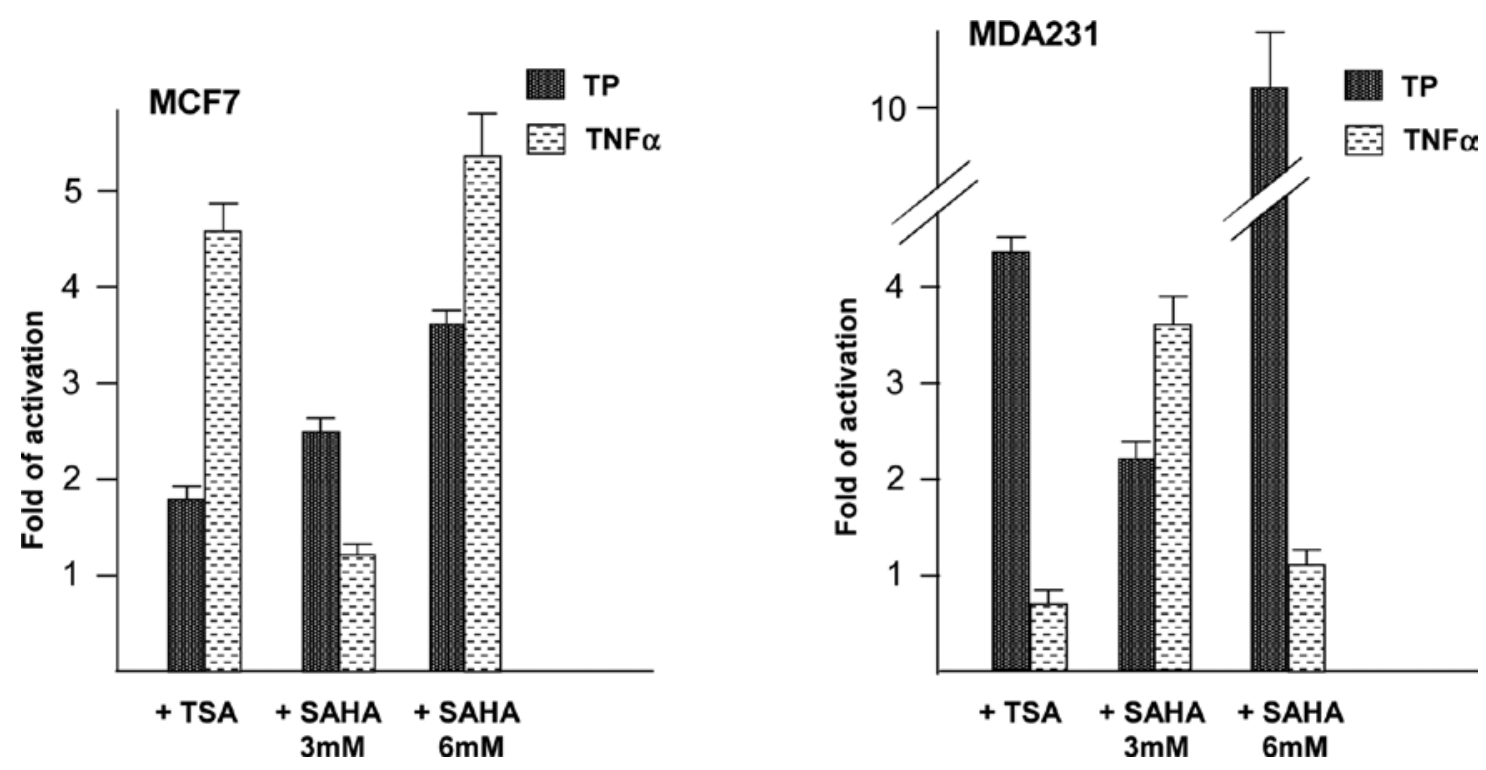

Figure 5. Effects of TSA and SAHA on TP and TNF $\alpha$ mRNA levels. MCF7 and MDA231 lines were treated with TSA (300 nM) and SAHA (3 and $6 \mu$ M) for $24 \mathrm{~h}$. TP and TNF $\alpha$ levels were evaluated as described in Materials and methods. Effects of TSA and SAHA are shown as fold of activation. The value of 1 corresponds to the mRNA levels present in the untreated cells. 
HDACi treatment may occur via an increase in TNF $\alpha$. This possibility was investigated by the assessment of TP and TNF $\alpha$ mRNA levels upon HDACi treatment. As shown in Fig. 5, a clear dissociation between TP and TNF $\alpha$ mRNA levels was detected in the MDA231 cells. In these cell lines, treatment with $300 \mathrm{nM}$ TSA or $6 \mu \mathrm{M}$ SAHA induced a significant increase in TP mRNA, but not TNF $\alpha$ mRNA. Alhough a dissociation was not evident in the MCF7 cells, our data strongly suggest that an increase in TP mRNA upon application of HDACi does not occur via an increase in $\mathrm{TNF} \alpha$ gene expression.

\section{Discussion}

In the present study, two major findings were noted. First, a good correlation between TP mRNA and protein levels was found in the breast cancer cell lines. Such a correlation was observed both under basal conditions and when cells were treated with HDACi. Therefore, our data indicate that the TP mRNA levels are the major determinants of TP protein levels. Thus, the lack of consistency noted between TP protein and mRNA levels as prognostic indicators or predictors of response to medical treatment is not attributable to a biological phenomenon, but to the different methods or scoring systems utilized to measure TP mRNA (quantitative RT-PCR) and TP protein levels (IHC). Our results are consistent with those recently reported by Ruckhaberle et al (18), who compared TP detection by immunohistochemistry (protein levels) and microarray (mRNA levels). When comparing microarray data with immunohistochemistry, no correlation was found for stained carcinoma cells. In contrast, the correlation with stromal staining was highly significant. Therefore, TP mRNA levels mainly reflect expression in non-cancerous cells, accounting for the discrepant results between mRNA and IHC analysis. According to this hypothesis, evaluation of TP by IHC is the most effective approach, allowing the distinct analysis of normal and tumor cells.

Second, an increase in TP mRNA and protein levels was noted upon treatment with HDACi. These compounds regulate the acetylation status of histones with subsequent effects on chromatin structure and gene transcription (23). SAHA and other HDACi also affect the acetylation of non-histone proteins and exhibit several biological effects including blockage of proliferation, generation of reactive oxygen species and induction of apoptosis (reviewed in refs. 23,24). SAHA was the first HDACi to be approved as a therapeutic agent in human tumors, particularly for cutaneous T-cell lymphoma (25). HDACi are currently used in several clinical trials, and their use in combination with other anticancer agents appears promising (26). Several trials have been published involving the treatment of patients with HDACi for different types of cancers (27). However, only a few studies reported correlative analyses aimed at investigating the potential mechanisms of action of these agents. Preclinical and clinical data indicate that HDACi may interfere with the expression of pro- and anti-angiogenic genes, suggesting a synergistic effect when HDACi are combined with anti-angiogenic agents such as the anti-VEGF antibody, bevacizumab (28). In addition, HDACi have been observed to potentiate the cytotoxicity of anthracycline-type topoisomerase (topo) II inhibitors such as doxorubicin, epirubicin and mitoxanthrone (29-31). Our data suggest that HDACi potentially sensitize tumor cells to treatment with capecitabine by enhancing the expression of TP. As a consequence, higher tumor TP expression is expected to increase the conversion of capecitabine to the active compound 5'-FU, resulting in a more favorable therapeutic effect. According to the results of our study and data reported in the literature, the combination of HDACi and capecitabine warrants investigation in clinical trials.

\section{Acknowledgements}

This study was funded by grants from MIUR to G.D. (PRIN no. 2007N8P32H_002; FIRB no. RBRN07BMCT). This research was performed under the auspices of the Associazione di Ricerca Traslazionale In Senologia (ARTIS). C.P. is supported by a grant from the Associazione Italiana per la Ricerca sul Cancro (AIRC) to G.D. (project no. IG 10296).

\section{References}

1. Friedkin M and Roberts D: The enzymatic synthesis of nucleosides. II. Thymidine and related pyrimidine nucleosides. J Biol Chem 207: 245-256, 1954.

2. Miyazono K, Okabe T, Urabe A, Takaku F and Heldin CH: Purification and properties of an endothelial cell growth factor from human platelets. J Biol Chem 262: 4098-4103, 1987.

3. Ishikawa F, Miyazono K, Hellman U, et al: Identification of angiogenic activity and the cloning and expression of plateletderived endothelial cell growth factor. Nature 338: 557-562, 1989.

4. Toi M, Rahman MA, Bando M and Chow LW: Thymidine phosphorylase (platelet-derived endothelial-cell growth factor) in cancer biology and treatment. Lancet Oncol 6: 158-166, 2005.

5. Miwa M, Ura M, Nishida M, et al: Design of a novel oral fluoropyrimidine carbamate, capecitabine, which generates 5 -fluorouracil selectively in tumours by enzymes concentrated in human liver and cancer tissue. Eur J Cancer 34: 1274-1281, 1998.

6. Gotanda T, Haraguchi M, Tachiwada T, et al: Molecular basis for the involvement of thymidine phosphorylase in cancer invasion. Int J Mol Med 17: 1085-1091, 2006.

7. Iltzsch MH, El Kouni MH and Cha S: Kinetic studies of thymidine phosphorylase from mouse liver. Biochemistry 24: 6799-6807, 1985.

8. Moghaddam A, Zhang HT, Fan TP, et al: Thymidine phosphorylase is angiogenic and promotes tumor growth. Proc Natl Acad Sci USA 92: 998-1002, 1995.

9. Li H, Suo Z, Zhang Y, Risberg B, et al: The prognostic significance of thymidine phosphorylase, thymidylate synthase and dihydropyrimidine dehydrogenase mRNA expressions in breast carcinomas. Histol Histopathol 19: 129-136, 2004.

10. Yang Q, Barbareschi M, Mori I, et al: Prognostic value of thymidine phosphorylase expression in breast carcinoma. Int $\mathrm{J}$ Cancer 97: 512-517, 2002.

11. Tominaga T, Toi M and Abe O; 5'-BC Study Group: Prognostic and predictive value of thymidine phosphorylase activity in earlystage breast cancer patients. Clin Breast Cancer 3: 55-64, 2002.

12. Liekens S, Bronckaers A, Pérez-Pérez MJ and Balzarini J: Targeting platelet-derived endothelial cell growth factor/ thymidine phosphorylase for cancer therapy. Biochem Pharmacol 74: 1555-1567, 2007.

13. Meropol NJ, Gold PJ, Diasio RB, et al: Thymidine phosphorylase expression is associated with response to capecitabine plus irinotecan in patients with metastatic colorectal cancer. J Clin Oncol 24: 4069-4077, 2006.

14. Layman RM, Thomas DG, Griffith KA, et al: Neoadjuvant docetaxel and capecitabine and the use of thymidine phosphorylase as a predictive biomarker in breast cancer. Clin Cancer Res 13: 4092-4097, 2007.

15. Puglisi F, Cardellino GG, Crivellari D, et al: Thymidine phosphorylase expression is associated with time to progression in patients receiving low-dose, docetaxel-modulated capecitabine for metastatic breast cancer. Ann Oncol 19: 1541-1546, 2008. 
16. Andreetta C, Puppin C, Minisini A, et al: Thymidine phosphorylase expression and benefit from capecitabine in patients with advanced breast cancer. Ann Oncol 20: 265-271, 2009.

17. Koopman M, Venderbosch S, van Tinteren H, et al: Predictive and prognostic markers for the outcome of chemotherapy in advanced colorectal cancer, a retrospective analysis of the phase III randomised CAIRO study. Eur J Cancer 45: 1999-2006, 2009.

18. Ruckhäberle E, Karn T, Engels K, et al: Prognostic impact of thymidine phosphorylase expression in breast cancer comparison of microarray and immunohistochemical data. Eur $\mathrm{J}$ Cancer 46: 549-557, 2010.

19. Beillard E, Pallisgaard N, van der Velden VH, et al: Evaluation of candidate control genes for diagnosis and residual disease detection in leukemic patients using real-time quantitative reverse-transcriptase polymerase chain reaction (RQ-PCR) - a Europe against cancer program. Leukemia 17: 2474-2486, 2003.

20. Bertrand P: Inside HDAC with HDAC inhibitors. Eur J Med Chem 45: 2095-2116, 2010

21. Kelly WK and Marks PA: Drug insight: Histone deacetylase inhibitors - development of the new targeted anticancer agent suberoylanilide hydroxamic acid. Nat Clin Pract Oncol 2: 150-157, 2005.

22. Zhu GH, Lenzi M and Schwartz EL: The Sp1 transcription factor contributes to the tumor necrosis factor-induced expression of the angiogenic factor thymidine phosphorylase in human colon carcinoma cells. Oncogene 21: 8477-8485, 2002.

23. Xu WS, Parmigiani RB and Marks PA: Histone deacetylase inhibitors: molecular mechanisms of action. Oncogene 26: 5541-5552, 2007.
24. Richon V: Cancer biology: mechanism of antitumour action of vorinostat (suberoylanilide hydroxamic acid), a novel histone deacetylase inhibitor. Br J Cancer 95: S2-S6, 2006.

25. Duvic M, Talpur R, Ni X, et al: Phase II trial of oral vorinostat (suberoylanilide hydroxamic acid, SAHA) for refractory cutaneous T-cell lymphoma (CTCL). Blood 109: 31-39, 2007.

26. Wong ST: Emerging treatment combinations: integrating therapy into clinical practice. Am J Health Syst Pharm 66: S9-S14, 2009.

27. Kristensen LS, Nielsen HM and Hansen LL: Epigenetics and cancer treatment. Eur J Pharmacol 625: 131-142, 2009.

28. Ellis L, Hammers H and Pili R: Targeting tumor angiogenesis with histone deacetylase inhibitors. Cancer Lett 280: 145-153, 2009.

29. Marchion DC, Bicaku E, Daud AI, Richon V, Sullivan DM and Munster PN: Sequence-specific potentiation of topoisomerase II inhibitors by the histone deacetylase inhibitor suberoylanilide hydroxamic acid. J Cell Biochem 92: 223-237, 2004.

30. Catalano MG, Fortunati N, Pugliese M, et al: Valproic acid, a histone deacetylase inhibitor, enhances sensitivity to doxorubicin in anaplastic thyroid cancer cells. J Endocrinol 191: 465-472, 2006.

31. Marchion DC, Bicaku E, Turner JG, Schmitt ML, Morelli DR and Munster PN: HDAC2 regulates chromatin plasticity and enhances DNA vulnerability. Mol Cancer Ther 8: 794-801, 2009. 